\title{
Working
}

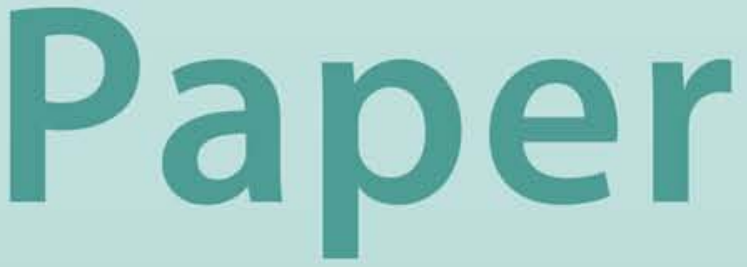


The Macroeconomic Effects of Migration from the New European Union Member States to the United Kingdom

Dora Iakova 


\title{
IMF Working Paper
}

\author{
European Department
}

\section{The Macroeconomic Effects of Migration from the New European Union Member States to the United Kingdom}

\author{
Prepared by Dora Iakova ${ }^{1}$ \\ Authorized for distribution by James Morsink
}

March 2007

\begin{abstract}
This Working Paper should not be reported as representing the views of the IMF. The views expressed in this Working Paper are those of the author(s) and do not necessarily represent those of the IMF or IMF policy. Working Papers describe research in progress by the author(s) and are published to elicit comments and to further debate.

The United Kingdom allowed workers from the ten new European Union member countries immediate access to its labor market after the accession in 2004. This paper uses a general equilibrium framework to explore the dynamic adjustment of the UK economy to the postaccession surge in immigration. Simulations show that immigration is likely to have positive effects on economic growth, capital accumulation, consumption, and the public finances.
\end{abstract}

JEL Classification Numbers: E21, E22, E27, J61, H55, F22

Keywords: Immigration, new EU member states, globalization, free labor movement Author’s E-Mail Address:iakova@imf.org

\footnotetext{
${ }^{1}$ I am grateful to Hamid Faruqee and Natalia Tamirisa for sharing the Multimod code and to Alina Carare for useful discussions. I would also like to thank James Morsink and participants in a seminar at the HM Treasury for helpful comments.
} 


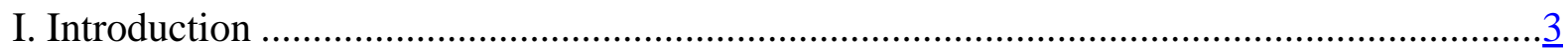

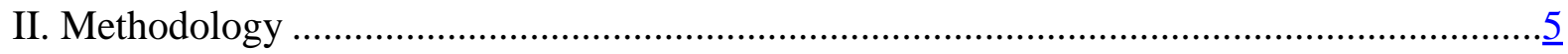

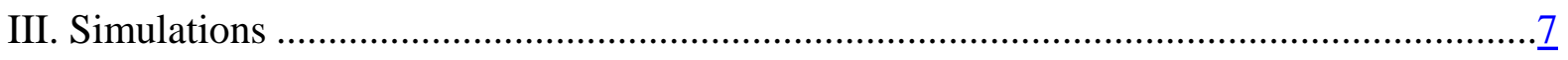

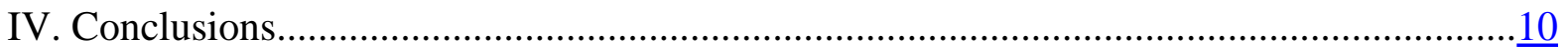

Appendix I. Description of the Model ........................................................................

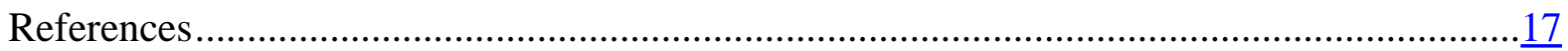




\section{INTRODUCTION}

The United Kingdom was one of the first countries to allow workers from the new European Union members immediate access to its labor markets in May 2004. ${ }^{2}$ The transitional arrangements set out in the Accession Treaty allow countries to choose to limit free labor movement for a period of up to seven years, with reviews of the policy after the second and fifth years. Only Ireland, the U.K., and Sweden chose not to impose restrictions in 2004. In the summer of 2006, Greece, Portugal, Finland, and Spain also decided to lift all restrictions for the ten accession countries, and six other member states adopted a more liberal policy. Starting in 2007, the U.K. will also accept workers from Bulgaria and Romania in certain sectors, although subject to tight quantity restrictions.

Although the existing statistics are imperfect, they suggest that a substantial number of workers from the new member states have arrived in the U.K. since 2004. Data sources on immigration include the Worker Registration Scheme, the International Passenger Survey, the Labor Force Survey, and National Insurance numbers data.

- $\quad$ All employees from the eight new member states (EU8) are required to register under the Worker Registration Scheme (WRS). Between May 2004 and September 2006, 510,000 people have registered, equivalent to an annual increase of approximately 0.7 percent of the work force. The WRS is the most frequently cited data source, however it is subject to two major caveats. First, it measures only the gross inflow of workers. There is no de-registration requirement, so people who work in the U.K. for a short time and then return to their country would still be counted in the statistics. Second, the self-employed are not required to register in the WRS.

- $\quad$ The International Passenger Survey (IPS), the official data source on migration, counts as immigrants those who state an intention to reside in the U.K. for at least a year upon entering the country. Based on that, the net flow of immigrants from the EU8 was 49,000 in 2004, and 64,000 in 2005. The survey is voluntary and does not capture people who change their intentions once in the country, even though it attempts to adjust for that error. In addition, only passengers coming through the principal air and sea routes are interviewed, while a substantial number of EU8 workers come in through the smaller airports. Overall, the survey is likely to understate net EU8 migration.

- $\quad$ The Labor Force Survey (LFS) provides an estimate of the stock of EU8-born residents in the United Kingdom. Based on that measure, between May 2004 and

\footnotetext{
${ }^{2}$ Citizens of Cyprus and Malta were allowed to work in the U.K. prior to 2004, so the change in the regime applied only to the remaining eight countries (Estonia, Czech Republic, Hungary, Poland, Lithuania, Latvia, Slovenia, and Slovakia). They will be referred to as EU8 in the rest of the text.
} 
September 2006, the number of EU8-born residents increased by 265,000 (Blanchflower et al, Table E), equivalent to an annual inflow of about 0.35 percent of the labor force. However, only households residing at their current address for at least six months are covered by the survey (people living in community establishments are not covered), so recent migrants and most temporary workers are excluded.

- $\quad$ National Insurance (NI) numbers are issued to all employed and self-employed individuals for tax and benefit purposes. Between April 2004 and March 2006, approximately 380,000 numbers were issued to EU8 nationals. Similar to the WRS, this statistic measures gross flows (unlike the WRS, it includes self-employed people).

Discussions of the macroeconomic effects of immigration have become a focus of policy and media attention, following this surge in labor flows from the new member states. The effects on growth, wages, and public finances are widely debated, even though the existing empirical evidence is still limited. Saleheen and Shadforth (2006) describe the characteristics of the recent EU8 migrants. Riley and Weale (2006) estimate that the inflow from the new member states in 2004-05 has contributed 0.2 percent to GDP growth. Using regional data, Gilpin et al. (2006) and Blanchflower et al. (2007) find that immigration is not related to the rise in unemployment in 2005/6.

Most of the existing theoretical and empirical literature on immigration is based on partial equilibrium, static models. ${ }^{3}$ These models, at best, provide guidance only to the expected short run effects on the labor market. Static analysis predicts that an increase in one factor of production reduces its relative price, therefore wages would fall after an increase in labor supply (or unemployment would rise in the presence of wage rigidities). However, open economies adjust dynamically, and the long-term effects on the labor market and the economy more generally are likely to differ from the short-term effects.

Using a general equilibrium dynamic model, this paper explores the likely evolution of the economy after a rise in accession-related immigration. Given the change in regulations governing labor mobility, post-accession migration represents a truly exogenous shock to labor supply, which makes it an ideal case for economic analysis. The model has an overlapping-generations structure, calibrated to reflect the demographic profile of the United Kingdom. The following questions are addressed. What is the impact of immigration on economic growth, capital accumulation, consumption, public finances, and the current account? Do the short-term macroeconomic effects of an immigration shock differ from the long-run effects? Can immigration help mitigate the adverse effects of population aging?

\footnotetext{
${ }^{3}$ A recent exception is Barrell et al. (2006). That study uses a general equilibrium macroeconomic model to illustrate the effects of changing net migration on output and unemployment in the U.K. and Germany.
} 


\section{Methodology}

The analysis is based on Multimod, a dynamic general equilibrium model with demographic features, developed at the IMF. ${ }^{4}$ Consumers are assumed to have a finite planning horizon, which affects their consumption/savings decisions. The production function is CobbDouglas, with capital and homogeneous labor as the factors of production. Investment behavior is based on the Tobin's Q-theory-investment growth accelerates when the expected marginal product of capital is greater than its cost. Perfect capital markets are assumed, allowing firms to borrow freely at the world interest rate. Government spending on pensions depends on the share of the population above retirement age (the pension payment per retiree is fixed as a share of GDP). An endogenous tax rate ensures that the ratio of government debt to GDP converges to a target level.

Demographic developments affect both the supply and the demand sides of the economy. On the supply side, earnings are presumed to be a good indicator of changes in relative productivity and labor supply that occur over an individual's working life. The pattern of earnings over time is hump-shaped-as workers accumulate experience, their productivity and earnings increase. After peaking in middle age, earnings gradually decline into retirement. The rate of participation in the labor market follows a similar pattern. Changes in the age structure of the population will thus affect the effective labor supply. On the demand side, individuals are assumed to smooth consumption based on their anticipated life-cycle income. Younger individuals tend to be net borrowers, since their current income is below their permanent income. Middle-age individuals, whose relative earning are at their peak, save for retirement. Therefore, changes in the age profile of the population will also have an impact on aggregate consumption and savings.

The age-earnings profiles for the United Kingdom are presented in Figure 1. They are estimated using data on actual hourly earnings from the Annual Survey of Hours and Earnings (ASHE) for the period 19982005. The earnings are adjusted for the labor force participation rates of the different age cohorts (obtained from the Labor Force Survey), and normalized relative to the per capita earnings of the youngest cohort. The earnings profile thus represents the average earnings per person

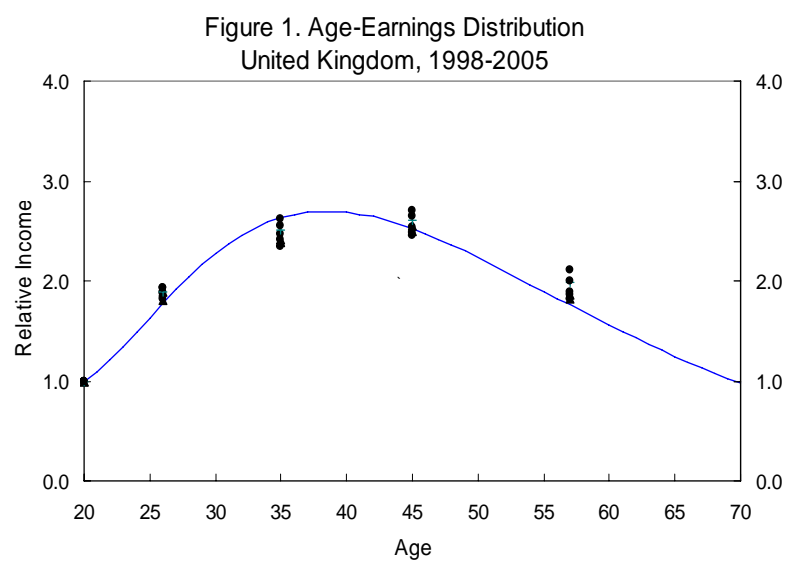

\footnotetext{
${ }^{4}$ See Laxton et al. (1998) for a description of Multimod. Faruqee and Laxton (2000) and Faruque (2002) contain a detailed discussion of the features of the model with demographics. Annex 1 contains a short description of the most relevant equations in the model.
} 
(not per worker) within each age category. The estimated earnings are shown at the approximate mid-point of the age ranges used in the ASHE. The relative earnings profiles have been relatively stable over the sample period. An exponential function is fitted through the age-earnings profiles to approximate the time-series pattern of a person's lifetime earnings:

$$
y(s, t)=a_{1} e^{-b_{1}(t-s)}+a_{2} e^{-b_{2}(t-s)}+\left(1-a_{1}-a_{2}\right) e^{-b_{3}(t-s)},
$$

where $y$ is relative labor income, $t$ is the current year, and $s$ is the year in which the individual entered the labor market. The $b$ parameters are estimated by non-linear least squares, using a grid search over the $a$ parameters. ${ }^{5}$ The estimated values are the following: $b 1=0.08, b 2=0.1$, b3=0.09, all significant at the 10 percent level.

The baseline scenario is calibrated to reflect the main features of the UK economy. The labor share of output is 69 percent. The steady state capital-output ratio is 2.3 , similar the historical average. The rate of capital depreciation is 5 percent. The rate of total factor productivity growth is assumed to be constant at 1.3 percent. The long-run real interest rate is assumed to be 4 percent. The initial level of the public debt is set at 40 percent of GDP, and the target debt level is also set at 40 percent (so there are no transitional dynamics if the pension system is kept in balance at all times). Since the results are presented in deviations from the baseline, they are quite robust to changes in the calibration parameters.

An immigration shock is introduced into the model as an increase in the number of young people in the economy. This is based on existing empirical evidence for the U.K., which suggests that more than 80 percent of the new EU-8 immigrants are between 18 and 34 years of age. Based on the latest Home Office Accession Monitoring Report (November 2006), 43 percent of all WRS applicants were aged between 18 and 24, and further 39 percent were between 25 and 34. Virtually all are working-98 percent of applications for National Insurance Numbers made by accession country nationals in the two years after accession were for employment purposes. ${ }^{6}$

The size of the immigration shock is chosen to broadly match the recent U.K. experience and academic estimates of the total migration potential from the new member countries. Specifically, it is assumed that 100,000 young workers from the new member states entered permanently the U.K. labor market in 2005 and 2006 respectively. ${ }^{7}$ A gradual reduction in

\footnotetext{
${ }^{5}$ For a more detailed explanation of this estimation, see Faruqee and Laxton (2000). It lists the various parameter restrictions that need to be satisfied, such as a non-negativity constraint on earnings.

6 To prevent “welfare tourism”, the U.K. has restricted access to social benefits for new EU-8 immigrants during the first year of employment. That may account for the fact that practically all immigrants hold jobs and the percentage receiving any social benefits is much smaller than that of the native population.

${ }^{7}$ The assumed size of net migration during 2004-06 is broadly based on the LFS statistics. It is higher than suggested by IPS (as discussed, this statistic may understate actual net migration from the EU8), but
}

(continued...) 
net migration is assumed over the next ten years as other countries open their labor markets and the number of potential immigrants declines (see Figure 2). Estimates by Boeri et al. (2005) and others, suggest that the net emigration potential of workers from the new member states (including Bulgaria and Romania) is equivalent to about 3 percent of their respective populations, with most of them expected to migrate within the first ten years after accession. The total net immigration to the U.K. assumed in this analysis amounts to about a quarter of that, reflecting the strong diversion of flows to the U.K. in the initial years of accession. Estimates of both actual and potential migration are highly uncertain, so this scenario should be taken only as an illustration and should not be interpreted as a forecast.

Figure 2. Assumed Net Migration

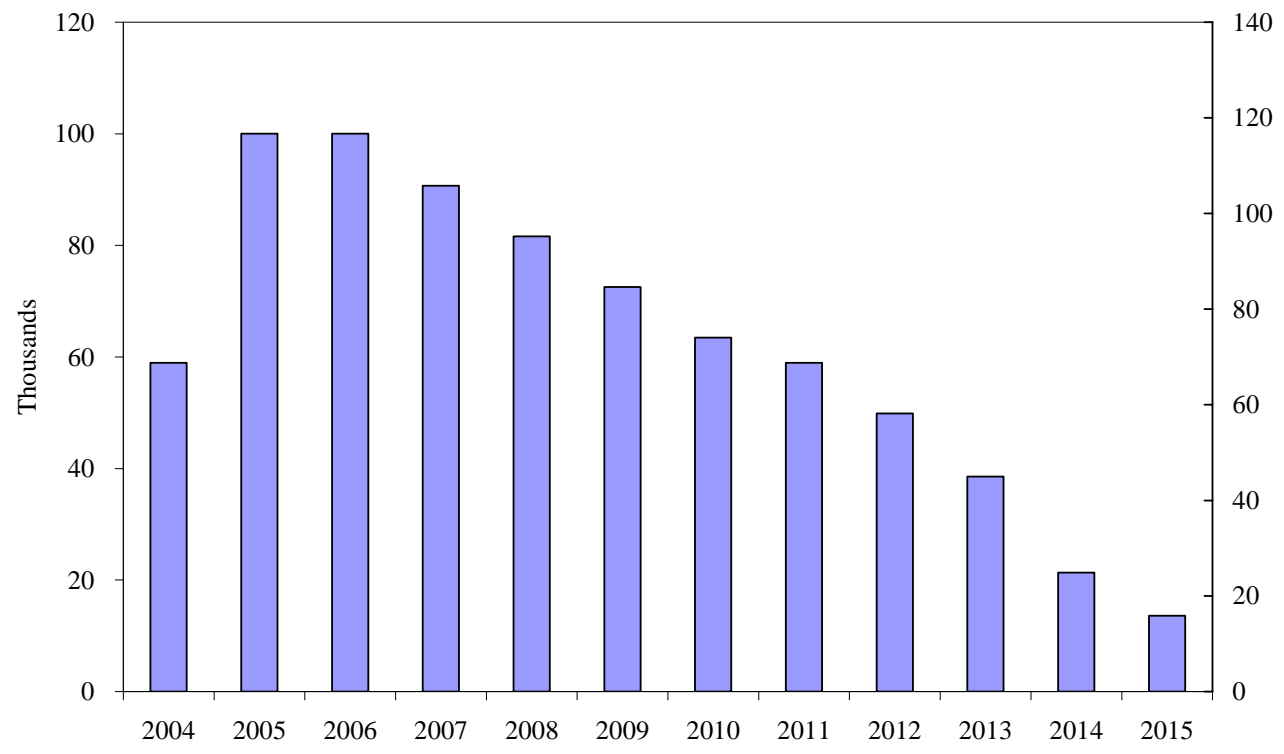

III. SimULATIONS

The simulations are performed in two steps. First, a baseline scenario based on the official projected population growth is estimated. The scenario uses historical data and the 2004 Government Actuary Department population projections through 2050. A gradual return to steady population growth is assumed thereafter (to ensure convergence in the model). Next, an immigration shock is introduced as an exogenous increase of the number of young individuals in the economy. ${ }^{8}$ The results are compared to the simulation based on the latest

significantly lower than the WRS and NI numbers (which measure gross inflows). The assumptions are made purely for illustrative purposes and do not represent a judgment on the actual net inflows.

${ }^{8}$ It is appropriate to make this assumption here since EU8 migration represents a truly exogenous shock, and its magnitude was largely unanticipated. Net migration from other countries is relatively steady and predictable, and is incorporated into the population and labor force projections made by the Office of National Statistics. 
population projections. The effects of the shock on the main macroeconomic variables are presented in Figure 3 (expressed in percentage point deviation from a no-immigration baseline).

Immigration boosts investment growth and the capital stock. Following a positive labor supply shock, the marginal product of capital goes up, while the marginal product of labor (and real wages) decline. That induces accumulation of capital to the point where its marginal product and marginal cost (determined by the world interest rate) are equalized. As capital increases, the marginal product of labor increases, reversing the initial downward pressure on real wages. In steady state, wage growth would be the same as before the immigration shock (assuming constant productivity).

Figure 3. Macroeconomic Effects of Immigration (Deviations from a no-immigration baseline level)
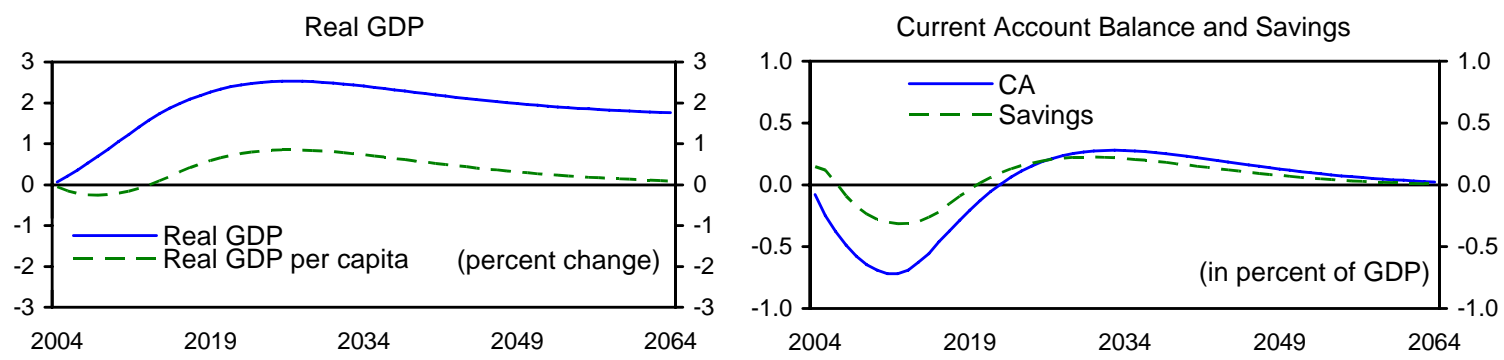

Investment and Capital Stock
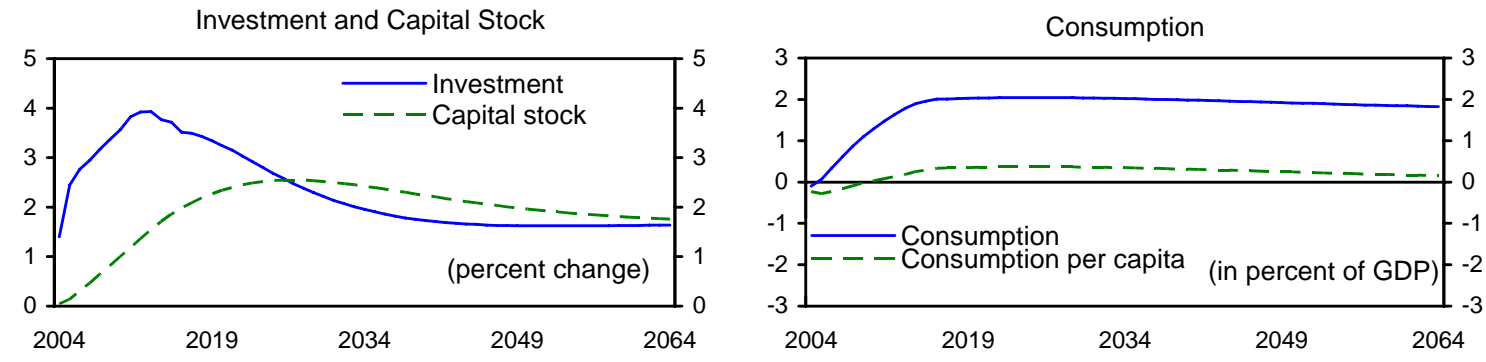

Pension Expenditure
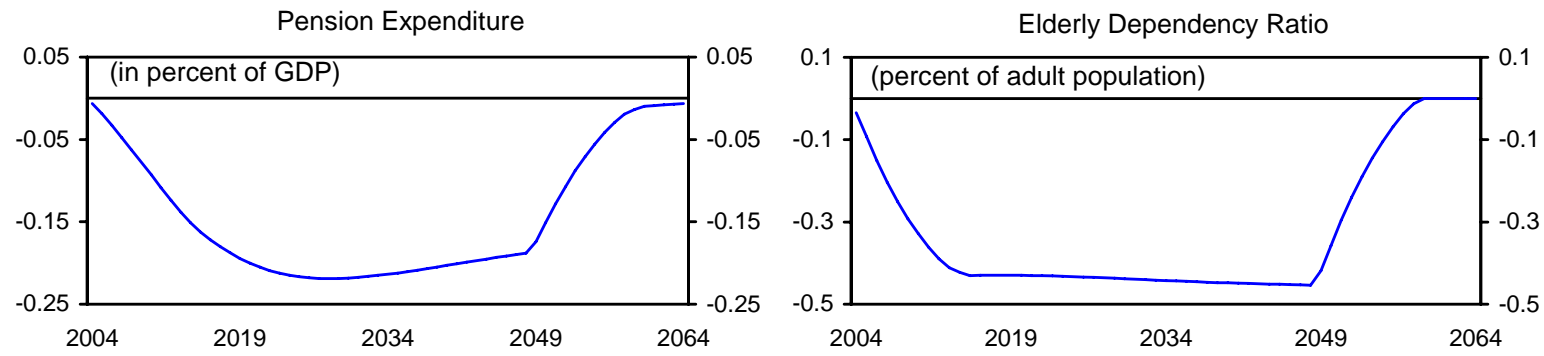

Both total and per capita output and consumption increase in the medium term. Total output and consumption are higher at all horizons as the population increases permanently. Per capita output declines for the first few years as the young immigrants are initially less productive than the average person (remember the hump-shaped profile of the age-earnings 
distribution). ${ }^{9}$ As they accumulate experience, productivity increases (above that of the average worker), raising per capita output. In the medium term, when immigrants reach the peak of their earnings potential, they save a substantial share of their earnings. Therefore the increase in consumption is less pronounced that the increase of output. As immigrants start to retire and consume their assets, per capita consumption becomes higher than per capita income. In the very long run, per capita real GDP and consumption return to baseline.

The current account initially deteriorates and then improves relative to the baseline. The deterioration in the initial years mainly reflects the rise in investment. The tendency of young workers to be net borrowers (or, in the case of immigrants, to send remittances abroad) also contributes to the initial deterioration of the current account. Later, when the immigrants' savings rate rises, the current account improves. As the EU8 workers reach retirement age, the current account returns to its initial value.

As the elderly dependency ratio declines, pension expenditure in percent of GDP declines. That would allow the government to either reduce debt or cut taxes. The simulation assumes a cut in taxes which boosts disposable income and consumption. This result holds as long as the average productivity of immigrants is similar to that of the total population, and their propensity to use publicly-provided benefits is also similar to the average. So far, very few EU8 immigrants have applied for social benefits, but one may expect that once they become eligible for all benefits, they will use them with roughly the same intensity as the native population.

Can immigration solve the fiscal problems related to aging? The EU8 migration wave represents a one-off positive demographic shock. Therefore, the positive fiscal effects would be temporary since the immigrants would also age. The net rates of migration necessary to offset the effect of aging in the long run are very high, so permanent productivity improvements and a well-designed pension system will continue to be important for ensuring fiscal sustainability.

The results are sensitive to some of the assumptions in the model. First, immigrants are assumed to have exactly the same skill distribution and productivity as the native workers. While this is broadly true for the stock of immigrants in the U.K. (see Salt and Millar, 2006), the sectoral distribution of immigrants from the new member states suggest that they may be

\footnotetext{
${ }^{9}$ This result assumes that the new immigrants have the same labor participation profile, and the same productivity as an average person of that age. In fact, immigrants may have higher labor participation rate (at least initially). Taking this into account could reduce the magnitude of the initial mild decline in per capita output. However, it is reasonable to assume that, over time, the labor force participation rate of the immigrants will converge to that of the native population (that has been true for the older immigrant cohorts, see Salt and Millar (2006)).
} 
less skilled than the average worker. ${ }^{10}$ That would reduce the estimated effects. Second, the model assumes perfect flexibility in the labor and goods markets: there is no unemployment and economic output is continuously at potential. Relaxation of these assumptions could influence the adjustment dynamics. For example, the minimum wage sets a floor on the adjustment of real wages in some unskilled occupations. That could lead to a rise in unemployment. Third, the production function is assumed to be Cobb-Douglas. Changing the form of the production function (for example allowing for worker complimentarity) ${ }^{11}$ could produce higher positive effects. Finally, the magnitude of the macroeconomics effects is proportional to assumed size of the migration shock. If the model is extended to include a fixed factor of production (land), the effects would vary with the size of the shock.

\section{Conclusions}

The results of this analysis suggest that the macroeconomic effects of immigration from the EU8 are broadly favorable. Both total and per capita output and consumption increase in the medium term (as immigrants become more productive and investment growth accelerates). The current account initially deteriorates, reflecting the higher investment growth. Thereafter, the current account improves relative to the no-immigration baseline, before returning to steady state. Any initial downward pressure on wages would be temporary. As capital accumulates to meet the needs of the new workers, wages would grow in line with the rising marginal productivity of labor. The ratio of fiscal expenditure to GDP falls as the dependency ratio declines, allowing the government to reduce debt or temporarily cut taxes.

\footnotetext{
${ }^{10}$ However, it is possible that many new immigrants take jobs that do not correspond fully to their educational qualifications or innate skills. Over time, they may experience upward occupational mobility and become more productive as they accumulate location-specific human capital (see Barrett (2007) for evidence of that for Ireland).

${ }^{11}$ Both academic studies and the press often suggest that immigrants take jobs that are not attractive for the locals (or would not even exist if it was not for the immigrants). That increases the efficiency of the labor market and may induce an increase in the labor force participation of the local workers. That effect could be modeled as labor complimentarity in the production function. Borjas (2001) suggests another channel through which immigrants may improve economic efficiency_by locating in regions with the highest marginal product of labor.
} 


\section{APPENDiX I. DESCRIPTION OF THE MODEL ${ }^{1}$}

Demographics are modeled through cohort-specific birth rates and time-varying population growth. Life-cycle dynamics are generated using age-earnings profiles.

\section{Population Growth}

The basic equation for population dynamics is given by:

$$
\frac{\dot{N}(t)}{N(t)}=n(t)=b(t)-p(t),
$$

where $N$ is the population level and $n$ is the growth rate-equal to the difference between the "birth" rate $b$ and the death rate $p ;{ }^{2}$ dots denote derivatives with respect to time. Integratingup equation (1) over time yields an expression (up to a constant of integration) for the size of the total population at any moment in time:

$$
N(t)=e^{\int_{-\infty}^{t} n(v) d v}=e^{\int_{-\infty}^{t}[b(v)-p(v)] d v}
$$

Equation (2) shows that population size evolves according to the accumulation of past changes to its growth rate--i.e., the past difference between birth and death rates, which determines the size of the current population as growth factor times the size of the initial population.

\section{Dependency Ratio}

To facilitate analysis of demographic issues, measures that characterize the age distribution of the population are defined. Note that the size of the population, which until now has been defined in relative terms - vis-à-vis a reference population, can also be defined in aggregative terms - as the sum of existing individuals across all generations (indexed by s):

$$
N(t)=\int_{-\infty}^{t} n(s, t) d s=\int_{-\infty}^{t} b(s) N(s) e^{-p(t-s)} d s
$$

\footnotetext{
${ }^{1}$ This appendix follows Faruqee (2002), which contains a more detailed presentation. Laxton et al. (1998) has a full description of Multimod.

2 The birth rate $b$ is defined as the arrival rate of new adults and $N$ is the adult population. With constant birth and death rates, the number of agents belonging to a generation $s$ at time $s$ (i.e., at the time they are born), as a proportion of the contemporaneous population, is given by $n(s, s)=b N(s)$; the number survivors from that cohort at time $t$ is then given by $n(s, t)=b N(s) e^{-p(t-s)}$, where $p$ is the common death rate facing all agents.
} 
Similarly, an elderly dependency ratio is defined as the proportion of total population above a certain age:

$$
\phi(t)=\int_{-\infty}^{j(t)} \frac{n(s, t)}{N(t)} d s ; 0<\phi<1
$$

where $\phi$ measures the relative cohort size, as a share of the total population, of individuals older than some threshold age level--indexed by $j(t)$. Assuming that this age definition does not change, the index $j(t)$ moves with time to include new dependents, who have just reached the threshold age at each moment in time (i.e., $j^{\prime}(t)=1$ ). In the case where birth rates are constant, it can be shown that the dependency ratio $\phi$ would also be constant. ${ }^{3}$ Otherwise, the dependency ratio evolves over time according to the time derivative of equation (4) above:

$$
\dot{\phi}(t)=\frac{n(j(t), t)}{N(t)}-[p+n(t)] \phi(t)
$$

At each moment in time, the change in the dependency ratio is determined by the relative size of new dependents attaining the threshold age, less the proportion of the elderly $p \phi$ who die each period and accounting for growth in the population base $n \phi-$ i.e., the scaling variable.

\section{Age-earnings Profiles}

To incorporate the life-cycle dimension in the analysis, age-earnings profiles are constructed. Labor income initially rises with age and experience, before eventually declining with retirement. The individual labor input (which is inelastically supplied) varies in effective terms across agents from different generations. The effective labor supply (measured in efficiency units) is assumed to have the following time series pattern:

$l(s, t)=\left[a_{1} e^{-\alpha_{1}(t-s)}+a_{2} e^{-\alpha_{2}(t-s)}+\left(1-a_{1}-a_{2}\right) e^{-b_{3}(t-s)}\right] \mu(t) ; t \geq s, a_{1}>0>a_{2}, \alpha_{2}>\alpha_{1}>0$.

The exponential form is chosen for analytical tractability, and the specific choice of three inflection points is chosen to provide reasonable fit of the data. The last term $\mu$ in

\footnotetext{
${ }^{3}$ With steady population growth, the dependency ratio would settle down to its long-run value: $\bar{\phi}=e^{-\bar{b} \Delta}$, where $\Delta \equiv t-j(t)$ and $\bar{b}$ are constants.
} 
equation (6), which is not age-specific, represents general labor productivity growth that depends on economy-wide considerations (e.g., technology). ${ }^{4}$

Assuming equation (6) summarizes the age-specific features underlying differences in labor earnings across cohorts, the individual labor income can be expressed as the product of the aggregate wage rate and individual labor supply:

$$
y(s, t)=w(t) l(s, t)
$$

Thus, for a given wage rate, the relationship between age and earnings will exhibit a similar (hump-shaped) time profile as between age and labor supply; this profile has been documented empirically by age-earnings distributions in a broad cross-section of countries. ${ }^{5}$

Aggregating over all individuals renders total labor income:

$$
\begin{gathered}
Y(t)=\int_{-\infty}^{t} w(t) l(s, t) n(s, t) d s \\
=w(t) L(t)
\end{gathered}
$$

where $L$ is aggregate labor input, also measured in efficiency units.

Using the definition of individual labor supply in (6), one can also write $L$ as the sum of two components $L_{1}+L_{2}$-- representing aggregates of the factors underlying the ageearnings function in (7). ${ }^{6}$ In the presence of demographic dynamics, the law of motion governing the behavior of aggregate labor input can then be written as:

$$
\begin{aligned}
& \dot{L}(t)=\dot{L}_{1}(t)+\dot{L}_{2}(t) \\
& =b(t) N(t) e^{\mu t}+\left(\mu-p-\alpha_{1}\right) L_{1}(t)+\left(\mu-p-\alpha_{2}\right) L_{2}(t) .
\end{aligned}
$$

Intuitively, equation (9) defines changes in $L$ as depending on the effective labor supply of new entrants to the workforce and the death and productivity changes among existing workers.

\footnotetext{
${ }^{4}$ Henceforth, constant productivity growth: $\mu(t)=e^{\mu t}$ is assumed, where the aggregate productivity index at time zero is normalized to unity.

${ }^{5}$ See for example Jappelli and Pagano (1989). Reorganizing terms implicit in (7), one could also express labor income as a function of a cohort-specific wage $w(s, t)$--commensurate with individual productivity.

${ }^{6}$ Specifically, $L_{k}(t)=\int_{-\infty}^{t} l_{k}(s, t) n(s, t) d s$, where $l_{k}(s, t)=a_{k} e^{-\alpha_{k}(t-s)} e^{\mu t}$ for $k=1,2$ and, thus, $\dot{L}_{k}(t)=a_{k} b(t) N(t) e^{\mu t}-\left(\alpha_{k}+p\right) L_{k}(t)$.
} 


\section{Consumption}

Agents are assumed to maximize expected utility over their lifetimes subject to a dynamic budget constraint. Specifically, the evolution of financial assets $a(s, t)$ for an individual or household is determined by its saving, equal to the difference between income and consumption:

$$
\dot{a}(s, t)=(r+p) a(s, t)+y(s, t)-\tau(s, t)-c(s, t)
$$

where $r$ is the interest rate, $y-\tau$ is disposable labor income, and $c$ is consumption, all expressed in real terms (units of consumption). ${ }^{7}$ Ignoring any capital market imperfections, consumption is based on an agent's permanent income. Explicitly, optimal consumption (with log utility) is given by: ${ }^{8}$

$$
c(s, t)=(\theta+p)[a(s, t)+h(s, t)] .
$$

where $\theta$ is the rate of time preference and $h(s, t)$ is a measure of an agent's human wealth-equal to the present value of future labor income. ${ }^{9}$ Because labor income and human wealth eventually decline over a person's lifetime with retirement, the saving behavior implied by equation (11) suggests that agents eventually build up financial wealth $a(s, t)$ to ensure a certain level of retirement consumption (Faruqee and Laxton, 2000).

Aggregating again, total consumption as a function of (financial and human) wealth can be expressed as follows:

$$
C(t)=(\theta+p)[A(t)+H(t)]
$$

where $A$ is aggregate financial wealth and $H$ is aggregate human wealth. Financial wealth consists of domestic equity and bond holdings and, in the open-economy case, holdings of

\footnotetext{
${ }^{7}$ The term $p w(s, t)$ in the dynamic budget constraint reflects the efficient operation of the life insurance or annuities market.

${ }^{8}$ For the simulations, constant relative risk aversion (CRRA) utility is assumed (see Blanchard, 1985).

${ }^{9}$ For a fixed real interest rate, individual human wealth can be written as: $h(s, t) \equiv \int_{t}^{\infty}[y(s, v)-\tau(s, v)] e^{-(r+p)(v-t)} d v$. Correspondingly, the dynamic equation for an individual's human wealth is given by: $\dot{h}(s, t)=(r+p) h(s, t)-[y(s, t)-\tau(s, t)]$. Given the shape of the age-earnings profile and assuming proportional labor income taxes --i.e., $\tau(s, t)=\tau y(s, t)$, note that human wealth can also be written as: $h(s, t)=h_{1}(s, t)+h_{2}(s, t)$, where $h_{k}(s, t)=\int_{t}^{\infty}(1-\tau) w(v) l_{k}(s, v) e^{-(r+p)(v-t)} d v$ for $k=1,2$.
} 
net foreign assets; $A / K+B+F$. As for aggregate human wealth--reflecting the present value of economy-wide labor income streams, its behavior can be characterized as follows:

$$
\begin{aligned}
& \dot{H}(t)=\frac{d}{d t} \int_{-\infty}^{t} h(s, t) N(s, t) d s \\
& =h(t, t) b(t) N(t)+r(t) H(t)-[Y(t)-T(t)],
\end{aligned}
$$

where $T$ is total labor taxes and $Y$ - $T$ is total disposable labor income. Equation (13) shows that the incremental change in the stock of aggregate human wealth is influenced by the additional human wealth of the newest generation. ${ }^{10}$

Equations (9) and (13) summarize the role of demographic dynamics for economic behavior through both supply-side and demand-side channels. On the supply side, changes in the demographic profile of the economy impact the supply of labor, given the differences across age groups summarized in the age-earnings profile. On the demand side, aggregate consumption and saving behavior will also be affected through aggregate human wealth dynamics in the face of life-cycle income and demographic change.

\section{Pension System}

A pension system can be introduced into the framework as follows. Consider first the simple case of a lump-sum transfer scheme:

$$
\operatorname{tr}(s, t)=\left\{\begin{array}{l}
-\alpha(t) ; s>j(t) \\
+\beta(t) ; s \leq j(t)
\end{array}\right.
$$

where the transfers $\operatorname{tr}(s, t)$ paid or received by individuals, depending on their age. Younger generations $(s>j(t))$ pay into the system while older agents or pensioners $(s \leq j(t))$ receive a benefit. Redefining the scheme in terms of payroll tax financing is straightforward. In that case, individual contributions would be proportional to wage income: $\alpha(s, t)=\tau_{s s} y(s, t)$.

For any transfer scheme, a full-financing condition can be written as follows:

$$
\int_{-\infty}^{t} \operatorname{tr}(s, t) N(s, t) d s=0
$$

\footnotetext{
${ }^{10}$ Given the shape of the labor income profile, the evolution of individual human wealth for the newest generation $h(t, t)$ at each moment in time is:

$\dot{h}(t, t)=\left(r+p+\alpha_{1}\right) h_{1}(t, t)+\left(r+p+\alpha_{2}\right) h_{2}(t, t)-(1-\tau) w(t) e^{\mu t}$
} 
This general condition must hold for the transfer scheme to be deemed fully financed (i.e., no unfunded liabilities from the transfer system). Full-financing in the specific case of lumpsum transfer is then given by:

$$
\frac{\beta(t)}{\alpha(t)}=\frac{1-\phi(t)}{\phi(t)} .
$$

Equation (16) shows the well known condition that the benefit-to-contribution ratio must equal the support ratio, defined as the number of working-age persons relative to elderly dependents. ${ }^{11}$ If full-financing is not satisfied, there would exist a financing gap (positive or negative) reflecting the degree of over- or underfunding. In the case of a shortfall, the social security deficit would have to be closed through increase in tax revenues or government borrowing.

\footnotetext{
${ }^{11}$ In the case of payroll taxes, individual contributions would be age-dependent, determined by social security taxes paid on individual labor income. In the simulations, individual social security benefits (in percent of GDP) are taken as exogenous policy parameters.
} 


\section{REFERENCES}

Barrell, R., C. Guillemineau, and I. Liadze, 2006, "Migration in Europe,” National Institute Economic Review, Vol. 198 (October), pp. 36-40.

Barrett, A. and D. Duffy, 2007, "Immigrants, Year of Arrival and Occupational Attainment: Looking for Evidence of Assimilation in Ireland,” ESRI, Ireland, mimeo.

Blanchard, O., 1985, “Debt, Deficits and Finite Horizons,” Journal of Political Economy, Vol. 93, pp. 223-47.

Blanchflower, D., J. Saleheen, and C. Shadforth, 2007, “The Impact of the Recent Migration from Eastern Europe on the UK Economy,” IZA Discussion Paper No. 2615.

Boeri, T. and H. Brucker, 2005, "Migration, Co-ordination Failures and EU Enlargement," IZA Discussion Paper 1600.

Borjas, G., 2001, “Does Immigration Grease the Wheels of the Labor Market?” Brookings Papers on Economic Activity 1, Brookings Institution, pp. 69-133.

Faruqee, H. and D. Laxton, 2000, "Life-Cycles, Dynasties, Saving: Implications for Closed and Small Open Economies," IMF Working Paper 00/126 (Washington: International Monetary Fund).

Faruqee, H., 2002, "Population Aging and Its Macroeconomic Implications: A Framework for Analysis,” IMF Working Paper 02/16.

Gilpin, N., Henty, M., Lemos, S., Portes J. and C. Bullen, 2006, “The Impact of Free Movement of Workers from Central and Eastern Europe on the UK Labor Market,” Working Paper No 29, Department of Work and Pensions, London, 2006

Jappelli, T. and M. Pagano, 1989, “Consumption and Capital Market Imperfections” An International Comparison,” American Economic Review, Vol. 79, pp. 1088-105.

Laxton, D., and others, 1998, MULTIMOD Mark III: The Core Dynamic and Steady-State Models, IMF Occasional Paper No. 164 (Washington: International Monetary Fund).

Riley, R. and M. Weale, 2006, “Immigration and its Effects,” National Institute Economic Review, Vol. 198 (October), pp. 4-9.

Saleheen, J. and C. Shadforth, 2006, “The Characteristics of Immigrants: A View from the Data,” Bank of England Quarterly Bulletin, 46(4), pp. 374-385.

Salt, J. and J. Millar, 2006, "Foreign Labor in the U.K.: Current Patterns and Trends,” Office of National Statistics, Labor Market Trends, October 2006. 